\title{
Un Comahue no tan frío. La Norpatagonia argentina en el proyecto represivo de la dictadura militar (1975-1983)
}

\section{A Comahue not so cold. The Argentinian Northpatagonia in the military repressive project of the dictatorship (1975-1983)}

Pablo Scatizza

\begin{abstract}
Resumen
En este trabajo se analiza de qué manera se insertó la Patagonia norte argentina dentro del esquema represivo que se desplegó en todo el territorio nacional antes y durante la última dictadura militar. Un esquema cuyo entramado habilitó dinámicas específicas y grados de autonomía propios aún dentro de una lógica de funcionamiento general que afectó a todo el país. Se enfatiza en torno a la gran importancia que se le otorgó en la práctica a una zona alejada de los grandes centros urbanos que, en la propia letra de la normativa castrense, no estaba incluida dentro de las denominadas "zonas calientes". Un interés que se verificó tanto en las acciones represivas concretas como en el armado institucional que se articuló para el desarrollo efectivo de dichas acciones.
\end{abstract}

Palabras clave: Dictadura militar, Represión, Norpatagonia argentina, Comahue

\begin{abstract}
This paper analyzes how Northern Patagonia Argentina was inserted into the repressive scheme deployed throughout the national territory before and during the military dictatorship. A scheme that enabled specific dynamics and relative autonomy despite being part of a logical operation that affected the whole country. It's emphasized around the importance that was given in practice to an area away from large urban centers that in the military documents was not included in the so-called "hot spots".
\end{abstract}

Key words: Military dictatorship, Repression, Northern Patagonia

\footnotetext{
* Argentino. Doctor en Historia. Docente del Profesorado y la Licenciatura en Historia, Universidad Nacional del Comahue. Neuquén/Bariloche, Argentina. Este estudio forma parte de la tesis doctoral del autor defendida en julio de 2013, en la cual se investigó en torno a la lógica represiva desplegada durante la última dictadura militar en Argentina, a partir de reducir la escala de observación sobre lo sucedido en la Patagonia norte. pscatizza@gmail.com
} 
Pablo Scatizza, Un Comahue no tan frío. La Norpatagonia argentina en el proyecto represivo de la dictadura militar (1975-1983)A Comahue not so cold. The Argentinian Northpatagonia in the military repressive project of the dictatorship (1975-1983), Revista Izquierdas, N²3, abril 2015, ISSN 0718-5049, IDEA-USACH, pp. 6680

\section{Introducción}

Giovanni Levi ha señalado cómo ciertos fenómenos que anteriormente se consideraban suficientemente descriptos y entendidos se revisten de significados completamente nuevos al alterar la escala de observación, y cómo al utilizar estos resultados es posible extraer generalizaciones mucho más amplias sobre un tema que se consideraba ya explicado'. Es esta una de las particularidades de la perspectiva microhistórica que adoptamos desde hace unos años, al proponernos investigar y analizar el desarrollo del plan represivo desplegado antes y durante la ultima dictadura militar en la Patagonia Norte, con la pretensión de completar y complejizar un poco más los estudios globales que se han propuesto acerca del terrorismo de Estado en la Argentina ${ }^{2}$. En todo este recorrido hemos indagado en torno a la dinámica represiva puesta de manifiesto en esta región del país, destacando, entre otras particularidades, el hecho de que su intensidad y magnitud tuviera características similares a la de los grandes centros urbanos, a pesar de no haber estado incluida por la normativa castrense dentro de las "zonas calientes", donde "la subversión ha desarrollado su mayor potencial”. En tal sentido, ha sido posible verificar la realización de sistemáticas tareas de inteligencia y reuniones de la comunidad informativa en tanto acciones previas e indispensables a los operativos desplegados a lo largo de todo el Comahue ${ }^{4}$; la adecuación de instituciones policiales para que funcionen como centros clandestinos de detención y torturas, así como la instalación de un centro/campo de concentración en el cual se pudo constatar -

1 Levi, Giovanni. "Sobre microhistoria”. En Peter Burke. Formas de hacer historia. Madrid: Alianza, 1991, pp. 119-143.

2 Cfr. Scatizza, Pablo. La Norpatagonia argentina bajo la Doctrina de Seguridad Nacional. Represión, dictadura y juicios de lesa humanidad: la causa Reinhold. Tesis de Doctorado en Historia. Buenos Aires: UTDT, inédita, 2013 [Disponible en http://goo.gl/mLrsDp]

3 Cfr. Directiva del Consejo de Defensa 1/75 "Lucha contra la subversión”. En adelante, Directiva 1/75

4 “Comahue”, “Alto Valle de Río Negro y Neuquén”, “Norpatagonia” son términos que se usarán de manera reiterada a lo largo de todo el trabajo. Aunque se refieran a territorios claramente diferenciados, esas denominaciones comparten entre sí grandes áreas en común, y en tal sentido dichos conceptos (cargados de contenido histórico y político) suelen ser utilizados de manera indistinta. Brevemente, cabe señalar que “Comahue" es la denominación que predominó en los 60-70 a partir de la diferenciación económica y política que se planteó desde los sectores de poder de la región frente a un Atlántico metropolitano, e incluye territorialmente a casi la totalidad de las provincias patagónicas de Río Negro y Neuquén. "Alto Valle”, en cambio, refiere puntualmente al área en forma de horqueta extendida unas decenas de kilómetros a lo largo de los ríos Limay y Neuquén, y poco más de cien a lo largo del río Negro. "Norpatagonia”, por último, es un concepto que se generalizó especialmente a partir de 1990 como parte de la difusión y la promoción de la provincia de Neuquén y la zona del Alto Valle como pseudo-potencia económica tras la venta del subsuelo particularmente, del petróleo y el gas- a capitales extranjeros, así como parte de la promoción turística de la Patagonia en el mercado global (Cfr. Kejner, Emilse. Los jóvenes como sujetos de los conflictos sociales de la Norpatagonia. Representaciones en la prensa gráfica (1969-1974). Tesis de Maestría en Análisis del Discurso, Facultad de Filosofía y Letras. UBA, 2011; Vapñarsky, César y Edith Pantélides. La formación de un área metropolitana en la Patagonia: población y asentamiento en el Alto Valle. Universidad de Texas: Centro de Estudios Urbanos y Regionales, 1987. 
Pablo Scatizza, Un Comahue no tan frío. La Norpatagonia argentina en el proyecto represivo de la dictadura militar (1975-1983)A Comahue not so cold. The Argentinian Northpatagonia in the military repressive project of the dictatorship (1975-1983), Revista Izquierdas, N²3, abril 2015, ISSN 0718-5049, IDEA-USACH, pp. 6680

así como sus pares de las grandes ciudades del país- su centralidad en el desarrollo y despliegue del dispositivo desaparecedor ${ }^{5}$. En el mismo sentido, se realizaron en esta parte del territorio operativos de secuestros previamente planificados en los que se desplegó una amplia logística; se le entregó la segunda comandancia de toda la “zona de seguridad” que incluyó a la Patagonia a uno de los represores más importantes que tuvo la dictadura militar el general Adel Edgardo Vilas (quien había comandado un año antes el "Operativo Independencia” en Tucumán)- y fueron destinados a la región personajes de la talla de Raúl Guglielminetti, quien tenía ya para entonces un amplio prontuario represivo. Elementos, entre otros, con los cuales ha sido posible completar y complejizar un poco más el entendimiento en torno a la sistematicidad de un proyecto represivo previamente planificado a escala nacional, y que más allá de sus relativos -y marcados- grados de autonomía que tuvo su puesta en práctica, siguió como en el resto del continente los preceptos delineados desde la Escuela Francesa y su "teoría de la guerra revolucionaria" tanto como por la Doctrina de Seguridad Nacional. Más de 30 personas desaparecidas y más de 120 casos denunciados ante la justicia ${ }^{6}$ de secuestros y torturas bajo el régimen militar, en una zona que por ellos mismos no era considerada peligrosa en términos de "subversión" (y en la que, de hecho, la "actividad subversiva" había sido baja hasta entonces y no se habían producido acciones guerrilleras), así como la violencia y la intensidad de las acciones represivas puestas en acto durante todo este período, son un clara muestra de que, más allá de los indicios que llevarían a pensar a la Norpatagonia como una región donde el proyecto represivo dictatorial se podría haber implementado con menor intensidad, la aplicación del plan de exterminio y terror se llevó a cabo con similares características que en el resto del país.

Asimismo, es necesario destacar el relativo grado de autonomía que tuvieron en su accionar los perpetradores locales en cada jurisdicción, dentro de la propia sistematicidad del plan represivo. Una libertad de acción que ciertamente estaba prescripta en la propia normativa militar, y que hizo posible que el dispositivo represor se convirtiera en algo verdaderamente dinámico ${ }^{7}$. En tal sentido, Gabriela Águila ha precisado que "existió una clara

5 Cfr. Calveiro, Pilar. Poder y desaparición. Los campos de concentración en Argentina. Buenos Aires: Colihue, 2006 y Calveiro, Pilar. "La experiencia concentracionaria”. En Clara Lida, Horacio Crespo y Pablo Yankelevich (comp.). Argentina, 1976. Buenos Aires: Fondo de Cultura Económica/Colegio de México, 2007, pp. 187-204. Un análisis teórico en torno a las modalidades de funcionamiento de estos espacios en la Norpatagonia puede verse en Scatizza, Pablo. "Centros clandestinos de detención en el Comahue. Una reflexion conceptual”. Contenciosa, $\mathrm{N}^{\circ} 2$, Segundo semestre 2014 [www.contenciosa.org]

6 Aún -año 2014- se siguen realizando en la ciudad de Neuquén los juicios por delitos de lesa humanidad cometidos en la Subzona 52. La causa principal que se instruye -y de la cual se desprenden otras subsidiariases el Expte 8736/05, "Reinhold, Oscar Lorenzo y otros s/ Delitos c/ la libertad y otros", del Juzgado Federal $N^{\circ} 2$ de Neuquén (en adelante, Causa Reinhold). Una parte de estos juicios ya fue juzgada, otras continúa en etapa de instrucción.

7 En el ítem c.1 de la Directiva 1/75, por ejemplo, se explicita que "(d)ada la actitud ofensiva asumida, las fuerzas tendrán amplia libertad de acción para intervenir en todas aquellas situaciones en que se aprecie puedan existir connotaciones subversivas". 
Pablo Scatizza, Un Comahue no tan frío. La Norpatagonia argentina en el proyecto represivo de la dictadura militar (1975-1983)A Comahue not so cold. The Argentinian Northpatagonia in the military repressive project of the dictatorship (1975-1983), Revista Izquierdas, N²3, abril 2015, ISSN 0718-5049, IDEA-USACH, pp. 6680

descentralización operativa (y funcional, podríamos agregar) entre los distintos circuitos represivos, no sólo a nivel de las zonas militares, sino también a nivel de las subzonas y áreas”, a pesar de que su organización fue proyectada a escala nacional y de que hubo, en efecto, un alto grado de coordinación entre los comandos de las distintas zonas de seguridad. Y subraya que fue esa dualidad lo que hizo que el ejercicio de la represión adquiriera modalidades y características específicas según las distintas regiones en las que se puso en práctica. Y en este sentido, si bien su trabajo no refiere específicamente a lo sucedido en la Patagonia, resulta interesante destacar que su hipótesis bien puede ser sostenida a partir del estudio que realizamos en esta región del país, que en el esquema territorial de las Fuerzas Armadas quedó circunscripta dentro de lo ellos mismos denominaron "Subzona 52".

En este trabajo nos dedicaremos precisamente a analizar cómo se insertó el Comahue en el proyecto represivo, exponiendo aquellos elementos que nos hacen sostener que la dinámica represiva desplegada en esta región contó con un alto grado de autonomía, especialmente en lo que refiere a su planificación y ejecución.

\section{La Norpatagonia como parte del plan}

El 6 de octubre de 1975 el gobierno nacional redactó y refrendó tres decretos en los que se delegaba en las Fuerzas Armadas la intervención directa en materia de seguridad interna, y en los que se expresó el objetivo concreto y explícito de aniquilar a la "subversión”". . Tales fueron los decretos 2770, 2771 y 2772 luego conocidos como "decretos de aniquilamiento", que extendieron a todo el país lo que ocho meses antes había sido puesto a prueba durante el denominado "Operativo Independencia. Tras aquel primer documento de carácter

8 Aguila, Gabriela. "La represión en la historia reciente argentina: fases, dispositivos y dinámicas regionales”. En Gabriela Aguila y Luciano Alonso (coord.). Procesos represivos y actitudes sociales. Entre la España franquista y las dictaduras del Cono Sur. Buenos Aires: Prometeo, 2013, p. 110. La distinción entre "control operativo" y "control funcional" no es menor en la lógica castrense, ya que en su normativa se hace permanentemente alusión a estos dos tipos diferentes de control por parte de alguna fuerza superior sobre otras subordinadas. El primero alude a que el control y autoridad que tiene quien lo ejerce se restringe al empleo de las fuerzas subordinadas y sus elementos (recursos humanos, medios, inmuebles, etcétera) específicamente en las misiones encomendadas u ordenadas expresamente, quedando bajo responsabilidad de esas fuerzas todo lo concerniente a cuestiones logísticas propias de su funcionamiento, así como las cuestiones disciplinares, la coordinación, la dirección y organización interna. Por otro lado, el "control funcional" implica la subordinación de una determinada fuerza u organismo a la superioridad, de todo lo concerniente a su dirección y coordinación, incluyendo su funcionamiento interno. En este sentido, el relativo grado de autonomía (y no hay que perder de vista que fue relativo, no total) que refiere la autora, se verificó en ambos aspectos.

9 Cabe recordar que por entonces el Ejecutivo nacional se encontraba bajo la presidencia de la viuda de Perón, María Estela Martínez. No obstante, en esa primera semana de octubre la mandataria se encontraba de licencia y los tres decretos firmados en esos días fueron sancionados en su ausencia por el entonces presidente provisional del Senado a cargo del Poder Ejecutivo, Italo Lúder, junto con el resto del gabinete. El que habilitó las acciones del "Operativo Independencia” a comienzos de ese año, sin embargo, sí fue refrendado por Martínez. 
Pablo Scatizza, Un Comahue no tan frío. La Norpatagonia argentina en el proyecto represivo de la dictadura militar (1975-1983)A Comahue not so cold. The Argentinian Northpatagonia in the military repressive project of the dictatorship (1975-1983), Revista Izquierdas, $\mathbf{N}^{\circ}$ 23, abril 2015, ISSN 0718-5049, IDEA-USACH, pp. 6680

secreto del 5 de febrero de 1975 -el decreto "S" 261/75- el Comando General del Ejército quedó habilitado para "ejecutar las operaciones militares que sean necesarias a efectos de neutralizar y/o aniquilar el accionar de elementos subversivos que actúan en la provincia de Tucumán”, para lo cual se montó una estructura operativa e institucional al servicio del accionar represivo de esa fuerza. Se puso a su disposición y bajo su control operacional a las policías Federal y Provincial, y se instruyó a la Secretaría de Prensa y Difusión de la Presidencia para pusiera en marcha -a instancias del Comando General del Ejército- las operaciones de acción psicológicas que fueran necesarias para la aplicación del plan represivo ${ }^{10}$.

Y ello no sería más que un tubo de ensayo de lo que luego se extendería hacia todo el país mediante los decretos de octubre, en los cuales puede leerse como el punto de partida de todo un entramado normativo con el cual las Fuerzas Armadas actuarían los siguientes ocho años. En efecto, mientras los dos primeros decretos (2770/75 y 2771/75) creaban, respectivamente, el Consejo de Seguridad Interna compuesto por el Ejecutivo y el Ejército, y ponían bajo el control operacional de dicho Consejo al personal y los medios policiales y penitenciarios de todas las provincias, el tercero de esos decretos (2772/75) extendía la autorización a las Fuerzas Armadas para que ejecuten "las operaciones militares y de seguridad que sean necesarias a efectos de aniquilar el accionar de los elementos subversivos en todo el territorio del país". Días más tarde, el Consejo de Defensa dictaría la Directiva 1/75 "Lucha contra la Subversión" y, por su parte, el Comandante General del Ejército, Jorge Rafael Videla, hizo lo propio el 28 de octubre con la Directiva Secreta $N^{\circ} 404 / 75$ : documentos a través de los cuales se dispuso con total detalle cómo se preveía llevar a cabo tal aniquilación.

En el octavo ítem de la mencionada Directiva 1/75 quedó establecido un nuevo mapa de la Argentina en términos de seguridad; una nueva división territorial en la que los distintos cuerpos del Ejército ejercerían su comando para la operacionalización del plan represivo. Allí, se seguía a otra reglamentación -también secreta- que había sido creada durante el gobierno de Agustín Lanusse tres años antes: el Plan de Capacidades (MI) $72^{11}$. Así se ponía

10 Sobre el "Operativo Independencia”, ver Garaño Santiago. "El monte tucumano como 'teatro de operaciones': las puestas en escena del poder durante el Operativo Independencia (Tucumán, 1975-1977)”. Nuevo Mundo Mundos Nuevos [En línea], Cuestiones del tiempo presente. Puesto en línea el 29 septembre 2011, consultado el 23 septembre 2014. http://nuevomundo.revues.org/62119; Izaguirre, Inés y colaboradores. Lucha de clases, guerra civil y genocidio en la Argentina, 1973-1983. Buenos Aires: Eudeba, 2009; Kohan, Nestor. Los verdugos latinoamericanos. Las Fuerzas Armadas: de la contrainsurgencia a la globalización. Buenos Aires: Populibros, 2007; Novaro, Marco y Vicente Palermo. La dictadura militar (1976/1983). Del golpe de estado a la restauración democrática. Buenos Aires: Paidos, 2006; Vilas, Adel Edgardo. Diario de campaña. De enero a diciembre de 1975, s/l: s/e, 1977, mimeo

11 No pudimos hallar dicho documento, y sólo lo conocemos por la mención que de él se hace en la directiva analizada. En la Directiva 504/77 "Continuación de la ofensiva contra la subversión durante el período 1977/1978”, en la que el Comandante en Jefe del Ejército actualizó lo establecido en la mencionada Directiva 404/75, se hace referencia a dicho documento como "PFE-PC-(MI) Año 1972", donde PFE sería 
Pablo Scatizza, Un Comahue no tan frío. La Norpatagonia argentina en el proyecto represivo de la dictadura militar (1975-1983)A Comahue not so cold. The Argentinian Northpatagonia in the military repressive project of the dictatorship (1975-1983), Revista Izquierdas, N 23, abril 2015, ISSN 0718-5049, IDEA-USACH, pp. 6680

en práctica uno de los elementos clave del plan represivo y otra de las enseñanzas de la "escuela francesa" que los oficiales argentinos importarían desde París: la estrategia de zonificar el teatro de operaciones. La doctrina de la guerra revolucionaria gestada por la oficialidad gala establecía como uno de sus principales preceptos la necesidad de implementar esta división territorial del espacio a controlar, y ello explica esta medida impulsada desde el momento cero en que las Fuerzas Armadas se hicieron cargo de la "seguridad interior". Así, se dividió en tal sentido el mapa nacional en cinco Zonas de Defensa, cuyos límites coincidirían con los que demarcaban la jurisdicción de los cuatro Cuerpos de Ejército $-1^{\circ}, 2^{\circ}, 3^{\circ}$ y $5^{\circ}$ Cuerpo- más el Instituto Militar, y se los puso bajo el mando de sus respectivos comandantes. Cada zona quedaba dividida a su vez en subzonas y éstas en áreas. En este trabajo nos hemos focalizado en la denominada la Zona 5, que abarcó a los partidos del sur de Buenos Aires y las provincias patagónicas de Neuquén, Río Negro, Chubut, Santa Cruz y Tierra del Fuego. El comando de esta zona quedaría establecido en el V Cuerpo del Ejército de Bahía Blanca ${ }^{12}$.

En este esquema territorial, y bajo el comando de Zona 5 establecido en esa ciudad portuaria, toda la Patagonia se dividiría a su vez en cuatro "subzonas de seguridad" (51, 52, 53 y 54, respectivamente) a cargo de los comandos de Brigada de cada una de esas regiones, y éstas así mismas en "áreas" que quedaron bajo la responsabilidad de sus respectivas jefaturas de Batallones o Regimientos. En lo que respecta a la zona del Comahue que aquí nos ocupa, la provincia de Neuquén y casi la totalidad de la provincia de Río Negro pasarían a conformar la Subzona 52 (o Subzona 5.2), cuya conducción quedó a cargo del Comandante de la Brigada de Infantería de Montaña VI (BIM VI), con asiento en Neuquén capital. Circunscripta a esta subzona quedarían cuatro áreas de seguridad: el Área 521 que abarcaba a la región del Alto Valle de Río Negro y Neuquén, bajo el mando del Batallón de Ingenieros de Construcciones 181 (BIC 181) ubicado a unos tres kilómetros del centro de la capital neuquina; el Área 522 que abarcó la zona centro y norte de la provincia de Neuquén y tuvo como unidades responsables al Regimiento Infantería de Montaña (RIM) 10 de Covunco, el RIM 21 de Las Lajas, la Compañía de Esquiadores 6 de Primeros Pinos y el Batallón Logístico de Montaña 6 de Zapala; el Área 523 con jurisdicción en la zona sur de la provincia de Neuquén, que tuvo sus sedes en el RIM 26 y el Grupo de Artillería de Montaña 6 de Junín de los Andes, y el Regimiento de Caballería de Montaña 4 de San Martín de los Andes; por último, el Área 524 que abarcó la zona sur de la provincia de Río Negro y tuvo su base en la Escuela de Instrucción Andina, en San Carlos de Bariloche.

"Plan de la Fuerza Ejército". La denominación que optamos por utilizar aquí es la referida en la propia Directiva $1 / 75$ de donde surge el dato.

12 Para más detalle de todo lo referido a la zonificación y a la organización general del esquema represivo, ver Mittlebach, Federico. Punto 30. Informe sobre desaparecedores. Buenos Aires: Ediciones de La Urraca, 1987; Mántaras, Mirta. Genocidio en Argentina. Buenos Aires: Edición de la autora, 2005; Scatizza, Pablo, La Norpatagonia argentina bajo la Doctrina de Seguridad Nacional, ob. cit.. 
Pablo Scatizza, Un Comahue no tan frío. La Norpatagonia argentina en el proyecto represivo de la dictadura militar (1975-1983)A Comahue not so cold. The Argentinian Northpatagonia in the military repressive project of the dictatorship (1975-1983), Revista Izquierdas, N 23, abril 2015, ISSN 0718-5049, IDEA-USACH, pp. 6680

\section{La hipótesis castrense}

Cuando la primera plana de las Fuerzas Armadas diseñó el plan represivo que pondrían en marcha a nivel nacional luego de sancionados los decretos de aniquilamiento, lo hizo en base a diferentes hipótesis respecto a cuál era el accionar considerado "subversivo" en las distintas zonas, subzonas y áreas de seguridad. Así, en la Directiva 404/75 quedó estipulado que el esfuerzo principal de la ofensiva castrense sería ejercido sobre "los grandes centros urbanos y áreas colindantes a lo largo del eje: Tucumán - Córdoba - Santa Fé - Rosario - Capital Federal y Gran Buenos Aires - La Plata - Bahía Blanca" (espacios territoriales que en la Directiva 1/75 el Consejo de Defensa calificó de "zonas calientes”). Además, dispusieron que las acciones a desarrollar en su alegada lucha contra la subversión previeran el control de áreas rurales con el fin de evitar que allí se conformaran nuevos frentes guerrilleros, en las que incluían a las provincias de Misiones, Chaco/Formosa, Salta/Jujuy, la zona montañosaboscosa de Neuquén y Río Negro y el delta del río Paraná. En este sentido, en términos normativos sólo la Cordillera de los Andes de la Subzona 52 se volvería un foco de atención, potenciado primero por la permanente "infiltración" de militantes sociales y políticos chilenos perseguidos por la dictadura de Pinochet, y luego por la hipótesis de conflicto que hacia 1978 se creó entre Argentina y Chile por el Canal de Beagle ${ }^{13}$.

Respecto al primer punto, en la Orden de Operaciones 5/75 (Lucha contra la Subversión) "Operación Comahue" se precisó que el control para evitar "frentes rurales" se extendería a las zonas de Villa La Angostura (Neuquén), El Bolsón y Bariloche (Río Negro), y resto de la zona montañosa/boscosa de la región, y que "cuando así convenga y a orden de esta Jefatura [la Escuela de Instrucción Andinal”, las operaciones deberían ejecutarse "integrándose y/o coordinándose al máximo con elementos de lucha contra la subversión de la República de Chile", lo cual iba a poder llevarse a cabo "si se mantienen enlaces permanentes y ágiles con personal militar o elementos de policía aduanera chilena (carabineros)" ${ }^{14}$. Por otro lado, las Fuerzas Armadas también previeron la existencia de "zonas potencialmente aptas" donde el "accionar subversivo" era considerado limitado, y dispusieron que esos lugares la represión fuera lo suficientemente intensa como para desalentar cualquier intento articulador de esas organizaciones, y lograr con ello transformar esas áreas en "zonas seguras" e "impedir su utilización como zonas de descanso o reorganización de los elementos subversivos" ${ }^{\$ 5}$. En esta última caracterización quedaría incluida el Área 521, aunque no de manera explícita en la directiva, cabe señalar, sino a la luz de las acciones llevadas a cabo. Allí el accionar represivo de la región sería más intenso, y donde se concentrarían los centros clandestinos de

13 La situación tenía un cierto cariz ezquizoide. Por un lado, las Fuerzas Armadas preveían y llevaban a cabo acciones coordinadas con sus pares trasandinos para el "aniquilamiento de la subversión” (Plan Cóndor mediante), y por otro tenían abierto un frente de conflicto en el extremo sur del continente que los tuvo al borde de una guerra.

14 Orden de Operaciones $5 / 75,4$

15 Directiva 404/75, 3 
Pablo Scatizza, Un Comahue no tan frío. La Norpatagonia argentina en el proyecto represivo de la dictadura militar (1975-1983)A Comahue not so cold. The Argentinian Northpatagonia in the military repressive project of the dictatorship (1975-1983), Revista Izquierdas, N²3, abril 2015, ISSN 0718-5049, IDEA-USACH, pp. 6680

detención más importantes (“La Escuelita”, la Comisaría 24 de Cipolletti y la Delegación de la Policía Federal, por ejemplo) y los lugares de alojamiento de detenidos políticos como la Unidad 9 del Servicio Penitenciario Federal.

Así como la instalación e institucionalización de espacios represivos como los centros clandestinos de detención que hasta entrado 1978 continuaron funcionando en la región, hay otros elementos que evidencian el interés de las Fuerzas Armadas por reprimir todo accionar político opositor en la región, que en su propia hipótesis de conflicto veían como una posibilidad (real o potencial). Uno de ellos es aquel que puede considerarse como el operativo de secuestros y detenciones ilegales ${ }^{16}$ de mayor despliegue realizado en todo este período, que se llevó a cabo con el objetivo de eliminar al PRT-ERP de la región a dos meses del Golpe. En su ejecución, el Ejército (que comandó el operativo) dio claras muestras del intenso trabajo de inteligencia realizado en la zona meses antes del golpe, y de cómo se construyeron en ese proceso hipótesis precisas del accionar de sus enemigos a combatir. Estos estaban todos vinculados entre sí de manera directa o indirecta, y fueron secuestrados durante un raíd represivo que se extendió entre el 9 y el 15 de junio de 1976, incluyó a seis localidades norpatagónicas y tuvo como víctimas a una treintena de hombres y mujeres, en su mayoría menores de 25 años, de las cuales nueve permanecen desaparecidas ${ }^{17}$.

Lo mismo quedó en evidencia cuando analizamos quiénes fueron los primeros objetivos de los represores, desde el momento mismo del Golpe: todas ellas militantes y activistas políticos reconocidos de la región -casi en su totalidad peronistas- que fueron secuestradas o ilegalmente detenidas desde la madrugada del 24 de marzo. Es decir que más allá de no estar incluida dentro de las denominadas "zonas calientes", no debe soslayarse el hecho de que en ningún momento los militares minimizaron el potencial y el accionar concreto que tenían ciertas organizaciones políticas y sociales en la zona, principalmente las ligadas a las distintas ramas del peronismo combativo (PB, Monteros, JP) y del marxismo-guevarismo como el PRT. Si a ello le sumamos la "necesidad” de Ejército de instaurar un centro/campo de concentración en esta Subzona, y a la intensidad que por momentos adquirieron los operativos de secuestros llevados a cabo durante los dos primeros años, son un claro indicio de que la zona no era tan "fría” como la supuso la hipótesis que se plasmó en las directivas

16 Es importante distinguir entre "secuestros” y “detenciones ilegales”, ya que no son lo mismo más allá de sus características similares y sus generalmente idénticas consecuencias a lo largo de todo este período: por secuestros nos referiremos a aquellas acciones de detención de personas en situaciones de clandestinidad, generalmente de noche -aunque esto no fue excluyente-, llevados a cabo por personal policial, militar o civil sin identificación, la mayoría de las veces con sus rostros cubiertos o camuflados. En cambio, las detenciones ilegales se producían generalmente a plena luz del día, muchas veces quienes las llevaban a cabo se identificaban -o era posible identificar a qué fuerza pertenecían-, y más allá de no contar con orden judicial alguna que ordenara dicha detención, las víctimas eran trasladadas a cárceles o comisarías previo a ser pasadas a la clandestinidad.

17 Cfr. Scatizza, Pablo. La Norpatagonia argentina bajo la Doctrina de Seguridad Nacional.. Ob. Cit. Cap 6.2 
Pablo Scatizza, Un Comahue no tan frío. La Norpatagonia argentina en el proyecto represivo de la dictadura militar (1975-1983)A Comahue not so cold. The Argentinian Northpatagonia in the military repressive project of the dictatorship (1975-1983), Revista Izquierdas, N 23, abril 2015, ISSN 0718-5049, IDEA-USACH, pp. 6680

de 1975 .

Si la Subzona 52 no estaba incluida entre las "zonas calientes" descriptas en la normativa militar, ¿por qué, entonces, semejante despliegue represivo? Una de nuestra hipótesis es que la región era una zona "potencialmente apta" para el desarrollo de la "subversión", en especial el Alto Valle de Río Negro y Neuquén, y eso era algo que las Fuerzas Armadas locales sabían, más allá de no estar definida esa característica en la normativa militar elaborada en Buenos Aires. En tal sentido, si bien no aparece expresado en los documentos estudiados a lo largo de nuestra investigación, los perpetradores no pudieron haber soslyado la intensa actividad político-militante que vivió la región entre fines de los sesentas y comienzos de los setentas. En especial la conflictividad social signada por puebladas, huelgas obreras y movimientos estudiantiles. Sumariamente, ya que no es objetivo de este trabajo ahondar en estos acontecimientos, basta con tener en cuenta los levantamientos populares en Cipolletti y General Roca (conocidos como "el Cipolletazo" y "el Rocazo", ocurridos en septiembre de 1969 y junio de 1972, respectivamente ${ }^{18}$ ); las huelgas obreras como la de los trabajadores de la represa de El Chocón ("el Choconazo") entre diciembre de 1969 y febrero de $1970^{19}$; y el gran movimiento estudiantil que se conformó a principios de los setentas y que se extendió hasta entrado el gobierno de facto en torno a la nacionalización de la Universidad del Neuquén (luego de ello, Universidad Nacional del Comahue) ${ }^{20}$. Todos ellos fueron indudablemente momentos de gran agitación social, donde la militancia política y la lucha por los derechos humanos comenzaría a construirse y gradualmente consolidarse como un ethos del espacio valletano, en especial de la ciudad de Neuquén y sus alrededores. Y tal fue así, que más allá del intermezzo dado por el período de la gran represión dictatorial (en el cual más allá de la evidente merma, sería interesante analizar qué sucedió con toda esa movilización durante la segunda mitad de los setentas, cómo se mantuvieron vivos -o no- esos

18 Ambas experiencias, sin embargo, no deben considerarse insurrecciones como las que ocurrieron en Córdoba o Rosario en el mismo período, ya que estas últimas si bien cuestionaban al régimen imperante, también -y sobre todo- ponían en tela de juicio el propio sistema de gobierno. Las puebladas, en cambio, fueron mucho más limitadas. Partían de reivindicaciones locales y se expresaban a través de sus vecinos y organismos comunales, alentaban un cambio de figuras en el gobierno o ayuda económica del gobierno nacional, pero no mucho más que eso. Cfr. Pozzi, Pablo y Alejandro Schneider. Los setentistas. Izquierda y clase obrera. 1969-1976. Buenos Aires: Eudeba, 2000, p.55. Para el caso específico del "Cipolletazo", ver Aufgang, Lidia. Las puebladas: dos casos de protesta social. Cipolletti y Casilda. Buenos Aires: Centro Editor de América Latina, 1989 y Scatizza, Pablo. Violencia y conflictos sociales. Representaciones del diario Río Negro durante el onganiato. Tesis de Licenciatura, Universidad Nacional del Comahue, 2005, inédita [disponible en http://goo.gl/aexWxI]; para el "Rocazo" ver Spángaro, Yanina. Fuenteovejuna lo ha hecho. La rebelión popular y los sentidos del Rocazo. Viedma: Fondo Editorial Rionegrino, 2011.

19 Cfr. Chaneton, Juan. Dios y el diablo en la tierra del viento. Cristianos y marxistas en las huelgas de El Chocón. Buenos Aires: Catálogos, 2005; Quintar, Juan. El choconazo (1969-1970). Neuquén: Educo, 1998

20 Cfr. Echenique, José. “El movimiento estudiantil universitario del Comahue (1970-1976)”. En Orietta Favaro (coord). Sujetos sociales y políticas: historia reciente de la Norpatagonia argentina. Buenos Aires: La Colmena, 2005 
Pablo Scatizza, Un Comahue no tan frío. La Norpatagonia argentina en el proyecto represivo de la dictadura militar (1975-1983)A Comahue not so cold. The Argentinian Northpatagonia in the military repressive project of the dictatorship (1975-1983), Revista Izquierdas, N²3, abril 2015, ISSN 0718-5049, IDEA-USACH, pp. 6680

espacios, etc.), creemos que es posible pensar aquellos años que en términos estructurales sirven de puente entre las dos últimas dictaduras militares, como una suerte de "acumulación originaria" de aquello que Ariel Petruccelli, al conceptualizar la cualidad combativa que caracteriza a la capital neuquina y su comarca petrolera desde mediados de los noventa, ha dado en llamar contracultura de la protesta ${ }^{2 I}$.

Sin perjuicio de esto último, la dinámica con la que se desplegó la represión en la Norpatagonia deja en evidencia, una vez más, que la "lucha contra la subversión" no fue un objetivo en sí mismo del proyecto militar, ni su meta principal. Sin dudas fue sustancial, pero no mucho más otra serie de propósitos que explican la dictadura militar en toda su complejidad. Entre otros, la intención de romper con una forma de entramado social y político que atentaba en América Latina contra la hegemonía de los valores occidentales, capitalistas y cristianos; o la voluntad de consolidar un modelo político y económico capitalista dependendiente que había mostrado serias debilidades frente a los conflictos de clase, revueltas y revoluciones que se estaban desarollando a lo largo del continente suramericano; tanto como adaptar -o terminar de adaptar- dicho modelo a la dinámica del capital financiero internacional en franco avance. Incluso, podría incluso leerse en la "lucha contra la subversión” un medio para estos fines señalados, antes que un fin. Como fuere, lo que aquí nos interesa destacar es que la lógica represiva puesta en práctica en la Norpatagonia pone de manifiesto un argumento más al momento de demostrar que la dictadura militar no se puede explicar sólo por la situación de violencia política que caracterizó a los años previos al golpe de Estado, si atendemos, especialmente, a que en esta región no hubo acciones guerrilleras que justificaran, bajo la óptica castrense, la dureza y la crueldad con la que se implementó el terrorismo estatal.

\section{El dispositivo represivo en el Comahue}

Como en el resto del país, en la Subzona 52 el plan de aniquilamiento ideado a escala nacional articuló bajo el precepto de la "lucha contra la subversión" a un conjunto de fuerzas de seguridad que potenciaron y tergiversaron su propia naturaleza represiva. En tal sentido, el rol desplegado por las policías provinciales de Río Negro y Neuquén, así como la Policía Federal desde su delegación local, fue determinte; en especial por el uso como centros de detención clandestina que se les dio a algunas de sus dependencias a partir del mismo día del golpe. Un papel indispensable de la trama represiva y sin cuya ponderación sería imposible

21 Dice el autor que si bien no su intención definir con precisión esa contracultura, toda vez que sus límites son borrosos y sus características distintivas borrosas, sí "puede decirse que sus miembros comparten una serie de valores y de prácticas sociales: cierto anhelo de igualdad, una aspiración más o menos vaga de cambio social, un genérico 'anti-imperialismo', la protesta y el reclamo vistos como un valor positivo, una mirada crítica sobre el mundo y la sociedad en que viven, la organización y la movilización populares convertidas casi en una forma de vida, la importancia concedida a los derechos humanos, la oposición al MPN, cierta 'conciencia de clase', etc.”, Cfr. Petruccelli, Ariel. Docentes y piqueteros. De la huelga de ATEN a la pueblada de Cutral Có. Buenos Aires: Coedición El Cielo por Asalto / El Fracaso, 2005, p. 22 
Pablo Scatizza, Un Comahue no tan frío. La Norpatagonia argentina en el proyecto represivo de la dictadura militar (1975-1983)A Comahue not so cold. The Argentinian Northpatagonia in the military repressive project of the dictatorship (1975-1983), Revista Izquierdas, N²3, abril 2015, ISSN 0718-5049, IDEA-USACH, pp. 6680

comprenderla en su totalidad, aunque no por ello exento de matices y con una dinámica propia que es necesario destacar. Tal como quedó estipulado en los decretos de aniquilamiento y en sus posteriores directivas militares, las fuerzas policiales de todas las provincias del territorio nacional quedaron bajo control operacional del comando de las Fuerzas Armadas de cada jurisdicción. En la mayoría de todos los hechos denunciados en los expedientes judiciales analizados ${ }^{22}$, la participación de dichas fuerzas en sus respectivas jurisdicciones fue crucial, tanto para liberar la zona o cortar calles donde se iba a realizar un operativo, como en la participación directa de las respectivas "comisiones de detención" y "grupos de tarea” que actuaron en esos raids represivos ${ }^{23}$. Y, sobre todo, por la utilización de sus dependencias como lugares de reclusión clandestina e ilegal.

Respecto a esto último, no podemos eludir unas breves referencias a los roles cumplidos por la Comisaría $24^{\circ}$ de Cipolletti, la Delegación de la Policía Federal y la Comisaría $4^{\circ}$ de Cutral Có. Si bien no fueron los únicos centros clandestinos de detención, sin dudas fueron los más importantes, fuera del espacio concentracionario por antonomasia que funcionó en la zona: "La Escuelita" de Neuquén ${ }^{24}$. En lo que respecta a la primera de las instituciones, fue superlativo el rol desplegado por aquella dependencia policial radicada en Cipolletti, localidad vecina a la capital neuquina ubicada sobre la margen Este del río Neuquén. Tanto en el expediente judicial analizado como de los testimonios de las víctimas que pasaron parte de su derrotero por esa comisaría, se ha podido verificar el funcionamiento de esa dependencia como centro clandestino de detención y tortura, en especial durante los primeros meses del gobierno dictatorial. Lo mismo puede decirse de la delegación neuquina de la Policía Federal, e incluso de la comisaría ubicada en pleno centro de Cutral Có ${ }^{25}$,

22 En especial, nos referimos al Expte 8736/05, "Reinhold, Oscar Lorenzo y otros s/ Delitos c/ la libertad y otros”, del Juzgado Federal N² de Neuquén.

23 No está de más precisar la diferencia entre las “comisiones de detención” y los "grupos de tarea”. Las primeras, cuya especificidad ya estaba determinada en el Anexo 3 al Plan del Ejército (Contribuyente al Proceso de Reorganización Nacionah), estaban conformadas por personal del Ejército y de las policías provinciales y Federal. Actuaban vestidos de civil o con uniforme y generalmente se identificaban al practicar las detenciones. Lo hacían apoyados por personal policial y/o militar, llevaban a cabo sus operativos en vehículos con identificación oficial y la mayoría de las veces procedían a golpear las puertas de las viviendas requiriendo de manera enérgica por las personas que buscaban, en vez de ingresar de manera violenta e intempestiva. Los grupos de tarea, en cambio, operaban de manera clandestina y mucho más violenta, en vehículos civiles, sin identificación o con identificaciones falsas, y sus integrantes actuaban vestidos de civil, con el rostro oculto (utilizando capuchas, bufandas, pañuelos) o directamente disfrazados. Estos grupos solían estar conformados por personal civil dependiente del Ejército y de la policías provinciales y Federal, y hay testimonios que dan cuenta incluso de cómo en algunos operativos participaron sujetos que no eran integrantes de ninguna fuerza armada, a cambio de dinero o influencias.

$24 \quad$ Un estudio pormenorizado de estos lugares de reclusión, así como su distinción conceptual, puede verse en Scatizza, Pablo. “Centros clandestinos de detención en el Comahue. Una reflexión conceptual”. Ob. cit.

25 Cutral Có es una localidad de la provincia de Neuquén, ubicada a 100 kilómetros de la capital. 
Pablo Scatizza, Un Comahue no tan frío. La Norpatagonia argentina en el proyecto represivo de la dictadura militar (1975-1983)A Comahue not so cold. The Argentinian Northpatagonia in the military repressive project of the dictatorship (1975-1983), Revista Izquierdas, N 23, abril 2015, ISSN 0718-5049, IDEA-USACH, pp. 6680

aunque esta última sólo hay funcionado como centro de detención clandestina durante las trágicas jornadas de junio, con las que concluyó el ya referido operativo para eliminar al PRT-ERP de la región. En estas tres instituciones una particularidad las une de manera sustancial, al tiempo que las distingue de otros centros de reclusión clandestina que funcionaron en la región y en el resto del país: eran públicos. Al mismo tiempo que se atendía a vecinos en el mostrador en la entrada de cada una de esas instituciones, se interrogaba y torturaban hombres y mujeres que estaba detenidos en alguna oficina de su interior. Las víctimas eran introducidas por la puerta principal esposadas y con sus rostros descubiertos, como si fueran detenidos legales, y dentro de esos lugares eran mantenidas generalmente sin tabicar, por lo cual pudieron reconocer no sólo el lugar donde se encontraban sino a sus torturadores e interrogadores. Por otro lado, no hay registros de intervención militar en esos espacios al momento de los interrogatorios y tormentos sufridos por las víctimas, más allá del control operacional que sin dudas tenían los oficiales del Ejército que cumplían sus funciones en esos edificios policiales.

En "La Escuelita", por el contrario, la situación fue muy diferente. Quienes allí ingresaban desaparecían y quedaban al arbitrio de sus verdugos, ahora sí exclusivamente militares. Allí, como en los grandes centros de concentración de detenidos que tuvo el gobierno dictatorial, la aniquilación era puesta en acto de manera sistemática y total. Una aniquilación que destruía cuerpos y mentes, pero que no necesariamente implicaba la muerte de quienes allí llegaban. Incluso a pesar de ser una opción que muchos reclamaron. Morir era un derecho que ya no pertenecía a las víctimas, y que los perpetradores se arrogaban a su antojo. Ubicada en territorio militar - ¿dcuál no lo era?-, se supo de La Escuelita sólo por rumores, y recién luego de concluida la dictadura se conoció su existencia física. Las víctimas allí encerradas estuvieron permanentemente vendadas y atadas de pies y manos a unas camas cucheta que estaban distribuidas en dos habitaciones. Sólo eran sacados de allí para ser interrogados o torturados en el galpón de chapa que estaba a un costado, bien para ser trasladados a algún otro lugar o para ser liberados, siempre vendados y en algún descampado.

\section{Autonomías}

Este entramado represivo que hemos analizado hasta acá y que se fue conformando desde al menos un año antes del golpe, le dio al proyecto de exterminio desplegado en la región una dinámica propia aún dentro de la lógica y la organización que mantuvo a nivel nacional, sobre todo en los primeros años del gobierno dictatorial. Una relativa autonomía que en la Subzona 52 se evidenció más hacia el interior de la oficialidad castrense que en las distintas fuerzas policiales y de seguridad, como sí sucedió en otras zonas de seguridad del país. En tal sentido, podríamos decir que en la Norpatagonia es posible verificar una autonomía represiva intraoficial, y no tanto una autonomía interfuerzas como sí parece haber existido en otras zonas. Dicho de otra manera, mientras que en lugares como Rosario o Buenos Aires se ha podido verificar un importante grado de autonomía por parte de las policias provinciales y federales respecto de las Fuerzas Armadas, lo que hemos podido observar en el despliegue represivo en la región es que esa autonomía se evidenció más por parte de la oficialidad castrense respecto de sus superiores, dentro del Ejército, más que por parte de las fuerzas 
Pablo Scatizza, Un Comahue no tan frío. La Norpatagonia argentina en el proyecto represivo de la dictadura militar (1975-1983)A Comahue not so cold. The Argentinian Northpatagonia in the military repressive project of the dictatorship (1975-1983), Revista Izquierdas, N 23, abril 2015, ISSN 0718-5049, IDEA-USACH, pp. 6680

policiales hacia ellos.

En efecto, en algunas regiones las fuerzas policiales parecen haber desplegado su accionar represivo con un significativo grado de autonomía respecto de las Fuerzas Armadas, tanto en la ejecución de esas acciones como en su planificación. Tal fue el caso, por ejemplo, del protagonismo que tuvo en todo este período el Jefe de la Policía de la provincia de Buenos Aires, Ramón Camps, "bajo cuya dirección se estructuró el llamado 'Circuito Camps' integrado por más de 20 centros clandestinos de detención distribuidos en nueve partidos del conurbano bonaerense y de La Plata" ${ }^{26}$. Asimismo, Gabriela Aguila ha destacado el papel superlativo que tuvo durante la represión desplegada en la ciudad de Rosario la figura del comandante retirado de Gendarmería, Agustín Feced, quien estuvo al frente de la policía provincial, desde donde constituyó un eficiente grupo de tareas y realizó las imprescindibles tareas de inteligencia previas a la planificación y la ejecución de las acciones represivas ${ }^{27}$. En la Subzona 52, en tanto, también fueron colocados al frente de las policías provinciales oficiales de alto rango del Ejército. Tal fue el caso del Teniente Coronel Osvaldo Laurella Crippa, quien hasta el momento de asumir como Jefe de la Policía de Neuquén el 25 de marzo de 1976 había sido Jefe de la División II Inteligencia del Estado Mayor General de la BIM VI. Algo similiar puede verificarse en la Policía de Río Negro, que desde el momento del Golpe quedó bajo el control operacional del Teniente $1^{\circ}$ Gustavo Vitón, quien también estaba cargo de la Compañía "A" del Batallón de Ingenieros de Construcciones 181 de Neuquén (donde estaba asentada "La Escuelita"). Sin embargo, si bien hay elementos para suponer que la dinámica propia que adquirían bajo su mando dichas acciones fueron realizadas con un relativo grado de independencia, ésta se evidenció más en términos funcionales propias de cada dependencia policial (manejo de personal, ejecución de las detenciones, situación de detención de las víctimas y demás) que en cuestiones operativas de fondo, las cuales no dejaron de ser controladas desde el Comando neuquino que tenía a su cargo la Subzona 52; en especial por el Destacamento de Inteligencia 182 o el D2 (Inteligencia) del Estado Mayor de dicho Comando ${ }^{28}$ desde donde se planificaban las acciones represivas desplegadas en la región.

En nuestro caso, cuando nos referimos a la relativa autonomía que tuvo la oficialidad castrense en el desarrollo de la represión aludimos a la independencia que tuvieron con relación al Poder Ejecutivo Nacional, al Consejo de Seguridad Interna, al Consejo de Defensa o al Estado Mayor Conjunto, desde donde emanaron las órdenes directrices para el desarrollo de la "lucha contra la subversión", tanto en la preparación de los operativos como en su desarrollo. Una autonomía que, como referimos al comienzo, había quedado de

26 Águila, Gabriela. “La represión en la historia reciente argentina...”. Ob. Cit., p.113

27 Águila, Gabriela. Dictadura, represión y sociedad en Rosario, 1976/1983. Un estudio sobre la represión y los comportamientos y actitudes sociales en dictadura. Buenos Aires: Prometeo, 2008, $1^{\circ}$ Parte

28 Ambas dependencias ubicadas físicamente en la misma manzana, en pleno centro de la capital neuquina. 
Pablo Scatizza, Un Comahue no tan frío. La Norpatagonia argentina en el proyecto represivo de la dictadura militar (1975-1983)A Comahue not so cold. The Argentinian Northpatagonia in the military repressive project of the dictatorship (1975-1983), Revista Izquierdas, $\mathrm{N}^{\circ}$ 23, abril 2015, ISSN 0718-5049, IDEA-USACH, pp. 6680

alguna manera "autorizada" en la propia letra de la normativa militar. Así, por ejemplo, la Directiva 1/75 dispuso en su punto 6, "Ideas rectoras", que la concepción estratégica estaría dividida en tres niveles: "Nacional", a cargo del Consejo de Seguridad Interna; "Conjunto", a cargo del Consejo de Defensa, con la asistencia del Estado Mayor Concjunto, y "Específico", a cargo de cada Fuerza, en su jurisdicción territorial, "en lo relativo al cumplimiento de la misión impuesta”" ${ }^{29}$ Y en tal sentido, prácticamente todas las acciones desplegadas en la región -salvo tres casos de secuestros en el Area 524 (Bariloche) que fueron llevados directamente a Buenos Aires- comenzaron y finalizaron en la propia Zona 5.

Un análisis de las autonomías en el despliegue represivo merece ser realizado con mayor precisión y con una reducción aún mayor de la escala de observación, tarea específica que no es la que nos hemos propuesto para este trabajo. Sin embargo, a partir de lo estudiado hasta acá, sí nos interesa dejar establecida la siguiente hipótesis al respecto: la dinámica del dispositivo represor adoptó, aún dentro de una misma lógica estructural, distintas modalidades y grados de autonomía relativa según los acciones realizadas y de acuerdo los objetivos específicos que perseguían los perpetradores en cada caso. Dicho en otros términos, es posible verificar que fue en función de las hipótesis represivas desarrolladas en cada caso y por cada jefatura de área lo que en última instancia habilitó -o no- la existencia de distintos grados de autonomía por parte de las distintas fuerzas policiales y de seguridad. Bajo este precepto, hubo raids delictivos como el mencionado operativo para eliminar al PRT-ERP de junio de 1976, en el cual actuaron todas las fuerzas de seguridad de Neuquén y Cutral Có bajo el comando del Ejército, y, a su vez, en coordinación con Bahía Blanca (Subzona 51) en cuyo principal centro clandestino de detención -también denominada "La Escuelita"terminaron siendo alojadas la mayor cantidad de víctimas. Al mismo tiempo, hubo operativos en los que la Policía Federal actuó con un alto grado de autonomía y relativa independencia de las Fuerzas Armadas, aunque en muchos de ellos estuvo presente dirigiendo tanto en los secuestros como los interrogatorios Raúl Guglieminetti, quien era Personal Civil de Inteligencia que dependía del Ejército y a cuyas oficinas se reportaba. O situaciones relativas con hechos más aislados, como las que protagonizaron fuerzas de Gendarmería Nacional actuando en la primera etapa de una acción -léase secuestro y traslado hasta un edificio oficial antes de ser llevadas a dependencias del Ejército tanto de Neuquén como de Bahía Blanca, o bien a la cárcel federal- y en los cuales también es posible verificar un cierto grado de libertad tanto operativa como funcional, más no en términos resolutivos respecto al destino final de las víctimas ${ }^{30}$.

29 Cfr. Directiva $1 / 75$ ob. cit., 2

30 Esta enumeración de casos se encuentran detalladas tanto en los Requerimientos de la Fiscalía Federal de Neuquén de los años 2009 y 2011 de la Causa Reinhold, así como en los Autos de Elevación a Juicio del Juzgado Federal de Neuquén de la misma causa, y en los fundamentos de los fallos del Tribunal Oral en lo Criminal Federal de Neuquén en causas "Reinhold" (2008) y "Luera” (2012). 
Pablo Scatizza, Un Comahue no tan frío. La Norpatagonia argentina en el proyecto represivo de la dictadura militar (1975-1983)A Comahue not so cold. The Argentinian Northpatagonia in the military repressive project of the dictatorship (1975-1983), Revista Izquierdas, N²3, abril 2015, ISSN 0718-5049, IDEA-USACH, pp. 6680

\section{Un cierre que abre}

Hemos visto hasta acá de manera bastante sumaria la forma en que la Patagonia norte argentina se insertó dentro del esquema represivo que se desplegó en todo el territorio nacional antes y durante la última dictadura. Un esquema cuyo entramado habilitó dinámicas específicas y grados de autonomía propios aún dentro de una lógica de funcionamiento general. Durante el recorrido, quedó en evidencia la gran importancia que se le otorgó en la práctica a una región que, en la propia letra de la normativa castrense, no sólo no estaba incluida dentro de las zonas calientes, sino que quedó reducida sólo "la zona montañosaboscosa de Neuquén y Río Negro" como un espacio "potencialmente apto para el desarrollo de un frente rural”. Un interés que se verificó tanto en las acciones represivas concretas que el Ejército y el resto de las fuerzas de seguridad llevaron a cabo, como en el armado institucional que se articuló para el desarrollo efectivo de dichas acciones. Si bien es cierto que en términos absolutos la cantidad de operativos represivos realizados en el Comahue no se puede comparar con los grandes centros urbanos, como tampoco puede hacerse con el número de víctimas de secuestros y desapariciones, sí es factible y necesario poner de relieve y ponderar los elementos cualitativos de esos operativos, las modalidades desplegadas y las lógicas perseguidas. De esta manera, será factible ver en su complejidad la manera en que se desarrolló un dispositivo represivo de gran escala como lo fue el desplegado antes y durante la última dictadura militar; planificado con alto grado de precisión para ser puesto en práctica en todo el territorio nacional, pero cuya ejecución concreta contó con significativos grados de autonomía a nivel local.

Recibido: 3 octubre 2014

Aceptado: 23 enero 2015

\section{Bibliografía}

Aguila, Gabriela. "La represión en la historia reciente argentina: fases, dispositivos y dinámicas regionales". En Gabriela Aguila y Luciano Alonso (coord.). Procesos represivos y actitudes sociales. Entre la España franquista y las dictaduras del Cono Sur. Buenos Aires: Prometeo, 2013

Águila, Gabriela. Dictadura, represión y sociedad en Rosario, 1976/1983. Un estudio sobre la represión y los comportamientos y actitudes sociales en dictadura. Buenos Aires: Prometeo, 2008

Aufgang, Lidia. Las puebladas: dos casos de protesta social. Cipolletti y Casilda. Buenos Aires: Centro Editor de América Latina, 1989

Calveiro, Pilar. "La experiencia concentracionaria". En Clara Lida, Horacio Crespo y Pablo Yankelevich (comp.). Argentina, 1976. Buenos Aires: Fondo de Cultura Económica/Colegio de México, 2007, pp. 187-204

Calveiro, Pilar. Poder y desaparición. Los campos de concentración en Argentina. Buenos Aires: Colihue, 2006

Chaneton, Juan. Dios y el diablo en la tierra del viento. Cristianos y marxistas en las huelgas de El Chocón. Buenos Aires: Catálogos, 2005

Echenique, José. "El movimiento estudiantil universitario del Comahue (1970-1976)”. En Orietta 
Pablo Scatizza, Un Comahue no tan frío. La Norpatagonia argentina en el proyecto represivo de la dictadura militar (1975-1983)A Comahue not so cold. The Argentinian Northpatagonia in the military repressive project of the dictatorship (1975-1983), Revista Izquierdas, N²3, abril 2015, ISSN 0718-5049, IDEA-USACH, pp. 6680

Favaro (coord). Sujetos sociales y políticas: historia reciente de la Norpatagonia argentina. Buenos Aires: La Colmena, 2005

Garaño Santiago. "El monte tucumano como 'teatro de operaciones': las puestas en escena del poder durante el Operativo Independencia (Tucumán, 1975-1977)”. Nuevo Mundo Mundos Nuevos [En línea], Cuestiones del tiempo presente. Puesto en línea el 29 septembre 2011, consultado el 23 septembre 2014. http://nuevomundo.revues.org/62119

Izaguirre, Inés y colaboradores. Lucha de clases, guerra civil y genocidio en la Argentina, 1973-1983. Buenos Aires: Eudeba, 2009

Kejner, Emilse. Los jóvenes como sujetos de los conflictos sociales de la Norpatagonia. Representaciones en la prensa gráfica (1969-1974). Tesis de Maestría en Análisis del Discurso, Facultad de Filosofía y Letras. UBA, 2011

Kohan, Nestor. Los verdugos latinoamericanos. Las Fuerzas Armadas: de la contrainsurgencia a la globalización. Buenos Aires: Populibros, 2007

Levi, Giovanni. "Sobre microhistoria”. En Peter Burke. Formas de hacer historia. Madrid: Alianza, 1991

Mántaras, Mirta. Genocidio en Argentina. Buenos Aires: Edición de la autora, 2005

Mittlebach, Federico. Punto 30. Informe sobre desaparecedores. Buenos Aires: Ediciones de La Urraca, 1987

Novaro, Marco y Vicente Palermo. La dictadura militar (1976/1983). Del golpe de estado a la restauración democrática. Buenos Aires: Paidos, 2006

Petruccelli, Ariel. Docentes y piqueteros. De la huelga de ATEN a la pueblada de Cutral Có. Buenos Aires: Coedición El Cielo por Asalto / El Fracaso, 2005

Pozzi, Pablo y Alejandro Schneider. Los setentistas. Izquierda y clase obrera. 1969-1976. Buenos Aires: Eudeba, 2000

Quintar, Juan. El choconazo (1969-1970). Neuquén: Educo, 1998

Scatizza, Pablo. Violencia y conflictos sociales. Representaciones del diario Río Negro durante el onganiato. Tesis de Licenciatura, Universidad Nacional del Comahue, 2005, inédita [disponible en http://goo.gl/aexWxI]

La Norpatagonia argentina bajo la Doctrina de Seguridad Nacional. Represión, dictadura y juicios de lesa humanidad: la causa Reinhold. Tesis de Doctorado en Historia. Buenos Aires: UTDT, inédita, 2013 [Disponible en http://goo.gl/mLrsDp]

--.--. "Centros clandestinos de detención en el Comahue. Una reflexion conceptual". Contenciosa, $\mathrm{N}^{\circ} 2$, Segundo semestre 2014 [www.contenciosa.org]

Spángaro, Yanina. Fuenteovejuna lo ha hecho. La rebelión popular y los sentidos del Rocazo. Viedma: Fondo Editorial Rionegrino, 2011

Vapñarsky, César y Edith Pantélides. La formación de un área metropolitana en la Patagonia: población y asentamiento en el Alto Valle. Universidad de Texas: Centro de Estudios Urbanos y Regionales, 1987

Vilas, Adel Edgardo. Diario de campaña. De enero a diciembre de 1975, s/1: s/e, 1977, mimeo

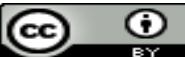

